\title{
CONGENITAL ADRENAL HYPERPLASIA
}

\author{
BY \\ S. RAITI* and G. H. NEWNS \\ From the Hospital for Sick Children, Great Ormond Street, London
}

(RECEIVED FOR PUBLICATION FEBRUARY 7, 1964)

Congenital adrenal hyperplasia was described in London by Phillips (1887) who reported four cases of spurious hermaphroditism in one family. Fibiger (1905) noticed that there was enlargement of the adrenal glands in some infants who had died after prolonged vomiting and dehydration. Butler, Ross, and Talbot (1939) reported a case which showed serum electrolyte changes similar to those of Addison's disease. Further developments had to await the synthesis of cortisone.

The work of Wilkins, Lewis, Klein, and Rosemberg (1950) showed that cortisone could alleviate the disorder and suppress androgen secretion. Bartter, Albright, Forbes, Leaf, Dempsey, and Carroll (1951) suggested that, in congenital adrenal hyperplasia, there might be a primary impairment of synthesis of cortisol (hydrocortisone, compound F) and a secondary rise of pituitary adrenocorticotrophin (ACTH) production. This was confirmed by Jailer, Louchart, and Cahill (1952) who showed that ACTH caused little increase in the output of cortisol in such cases. In the same year, Snydor, Kelley, Raile, Ely, and Sayers (1953) found an increased level of ACTH in the blood of affected patients.

Studies of enzyme systems were carried out. Jailer, Gold, Vande Wiele, and Lieberman (1955) and Frantz, Holub, and Jailer (1960) produced evidence that the most common site for the biosynthetic block was in the C-21 hydroxylating system. Eberlein and Bongiovanni (1955) showed that there was a C-11 hydroxylation defect in patients with the hypertensive form of congenital adrenal hyperplasia, and Bongiovanni (1961) and Bongiovanni and Kellenbenz (1962), showed that in some patients there was a further type of enzyme defect, a 3- $\beta$-hydroxysteroid dehydrogenase deficiency, an enzyme which is required early in the metabolic pathway. Prader and Siebenmann (1957) described a female infant who had adrenal insufficiency and congenital lipoid hyperplasia of the

\footnotetext{
- Present address: Steroid Training Programme at The Worcester Foundation for Experimental Biology, Shrewsbury, Massachusetts, U.S.A.
}

adrenal cortex. The external genital development in such cases was always female, and he suggested that there was an enzyme defect at an early stage of steroid synthesis both in the adrenal cortex and in the Leydig cells of the testis.

Grumbach and Wilkins (1956) published a review of 55 cases, and noticed that, while the disease varied among families, within each family it appeared to follow the same clinical pattern, i.e. salt-losers, hypertensives, etc. Childs, Grumbach, and Van Wyk (1956) estimated that the incidence of heterozygotes in the general population was 1 per 128; and Wilkins (1962) thought the incidence lay between $1: 50$ and $1: 100$.

With regard to salt loss, Eberlein (1958) reported that infants with this type of congenital adrenal hyperplasia required more desoxycorticosterone acetate (DCA) than did adults with Addison's disease. Urinary aldosterone excretion was measured by Blizzard, Liddle, Migeon, and Wilkins (1959) in the simple virilizing type of congenital adrenal hyperplasia and they found normal levels of aldosterone. In the salt-losing types they found reduced levels. This contrasted with earlier work by Prader, Spahr, and Neher (1955) who found increased levels of aldosterone in patients with the salt-losing type of congenital adrenal hyperplasia.

Cortisol production rates have now been measured. Kenny, Malvaux, and Migeon (1963) found that in newborns the rates were similar to those in adults when the figures were corrected for surface area. Infants with the salt-losing type of congenital adrenal hyperplasia were found to have lower than normal production rates.

Grumbach and Wilkins (1956) and Wilkins (1962) have reported their results with large series of patients in the U.S.A.

The present paper reports the patients seen at The Hospital for Sick Children, Great Ormond Street. No equivalent series showing the experience in Great Britain has been published hitherto.

In order to simplify the discussion of the disorder we have explained at the outset certain biochemical terms that are frequently used by clinicians. 
METABOLIC PATHMAY IN ADRENAL GLANDS

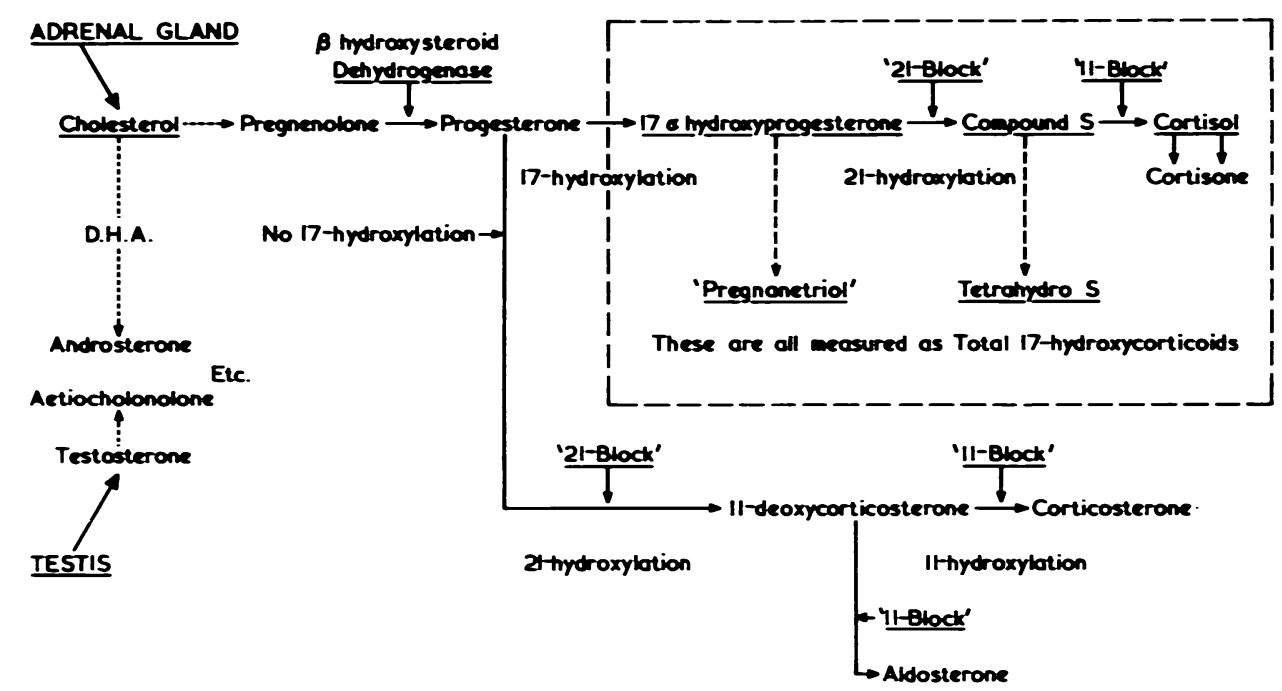

Fig. 1.

\section{Aetiology of Congenital Adrenal Hyperplasia}

The Formation of Cortisol (Hydrocortisone, compound F). The understanding of the defects in congenital adrenal hyperplasia is best achieved by reviewing the metabolic pathway in the formation of cortisol. A simplified version is given in Fig. 1. For the production of cortisol, three hydroxyl groups are added to progesterone by specific enzymes in a definite sequence. The numbers refer to the position on the steroid nucleus (Fig. 2).

C-17 hydroxylation occurs first. All subsequent substances now become 17-hydroxycorticoids and can be estimated as such in the urine. Defects causing a block in C-17 hydroxylation have not been described.

This is followed by C-21 hydroxylation. A block at this level occurs in the commoner forms of congenital adrenal hyperplasia, both in the simple and in the salt-losing types. The 17-hydroxymetabolites accumulate and are excreted in the urine as pregnanetriol which can be measured. Presence of this substance in the urine indicates that the block has occurred at the 21-hydroxylation level.

C-11 hydroxylation is the next and final stage. A block in enzyme action at this level leads to an accumulation of 'compound S' or 11-deoxy-cortisol. This substance is excreted in the urine as tetrahydro-S (THS) which may be measured specifically or detected by chromatography. Substances that lack this oxygen function in the 11-position are said

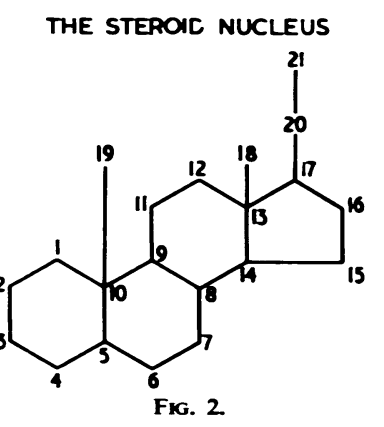

to be 11-deoxygenated. This forms the basis for the 11-oxygenation index as a test for diagnosis (Hill, 1960).

For the production of corticosterone and aldosterone, there is no initial C-17 hydroxylation, and these substances are not measured as 17-hydroxycorticoids. C-21 hydroxylation is the first step. This enzyme, therefore, is required both for the production of mineralocorticoid and of cortisol, and a deficiency of this enzyme has been postulated as an explanation for the salt-losing type of congenital adrenal hyperplasia. Indeed, Bongiovanni (1958) has suggested that the salt-losing type may merely represent a severer type of enzyme defect at this level

For the production of corticosterone, C-11 hydroxylation is the next step, whereas for the formation of aldosterone, an aldehyde group is required at position $\mathrm{C}-18$. 
Adrenal steroid secretion rates in adults have been measured and are listed in Table 1 . In infants, figures for the cortisol production rates in newborn babies have been estimated, using radioisotope techniques (Kenny et al., 1963). The mean production rate was found to be $3 \cdot 1 \mathrm{mg}$. per 24 hours. When corrected for surface area, these figures are similar to those of adults.

TABLE 1

NORMAL ADRENAL STEROID PRODUCTION RATES IN ADULTS

\begin{tabular}{|c|c|c|c|}
\hline Steroid & & $\begin{array}{l}\text { Production } \\
\text { Rate per } \\
24 \mathrm{hr} . \\
\text { (mg.) }\end{array}$ & Reference \\
\hline Cortisol (hydrocortisone) & . & $17-29$ & $\begin{array}{c}\text { Peterson and } \\
\text { Wyngaarden (1956) }\end{array}$ \\
\hline Corticosterone & . & $2-3$ & Peterson (1957) \\
\hline
\end{tabular}

\section{Explanation of Laboratory Terms}

(1) 17-ketosteroids (17-oxysteroids) are substances that have a ketone group $(=0)$ at position $\mathrm{C}-17$ on the steroid nucleus. Though the estimation is nonspecific, it is helpful in controlling treatment. The value includes such derivatives as dehydroepiandrosterone, androsterone, and aetiocholanolone. In circumstances where the production of $17-$ hydroxypregnane derivatives is very high, the 17-ketosteroids will be raised due to the conversion of about $5-10^{\circ}$ o of 17-hydroxypregnane derivatives. Values obtained in normal children are set out in Table 2 (Prout and Snaith, 1958).

TABLE 2

NORMAL DAILY 17-KETOSTEROID OLTPLT (PROUT AND SNAITH, 1958)

\begin{tabular}{|c|c|c|c|c|c|c|}
\hline \multicolumn{6}{|c|}{ Age-group (in years) } & \multirow{2}{*}{$\begin{array}{c}\begin{array}{c}\text { 17-Ketosteroids } \\
\text { (mg. } 24 \text { hr. }=\text { S.D.) }\end{array} \\
0.25=0.12 \\
0.78=0.46 \\
1.38=0.74 \\
4.96=2.06\end{array}$} \\
\hline $\begin{array}{l}0-1 \\
1-5 \\
6-10 \\
11-17\end{array}$ & $\begin{array}{l}\cdots \\
\cdots \\
\cdots\end{array}$ & $\begin{array}{l}\cdots \\
\ldots \\
\cdots\end{array}$ & $\begin{array}{l}\cdots \\
\cdots \\
\cdots\end{array}$ & $\begin{array}{l}\cdots \\
\cdots \\
\cdots\end{array}$ & $\begin{array}{l}\cdots \\
\cdots \\
\ldots\end{array}$ & \\
\hline
\end{tabular}

(2) Total 17-hydroxycorticoids are substances that have a hydroxyl group in the $\mathrm{C}-17$ position. They include all the substances shown in Fig. 1 and exclude steroids from other sources such as the testis. They represent a more specific estimation of the metabolic products in the pathway for production of cortisol. Values obtained in normal children are set out in Table 3.

(3) Pregnanetriol is an abnormal metabolite excreted in the urine of patients who have a block in 21-hydroxylation, and it can be measured.
TABLE 3

NORMAL DAILY TOTAL 17-HYDROXYCORTICOID OUTPUT (AFTER CLAYTON, EDWARDS. AND RENWICK. 1963)

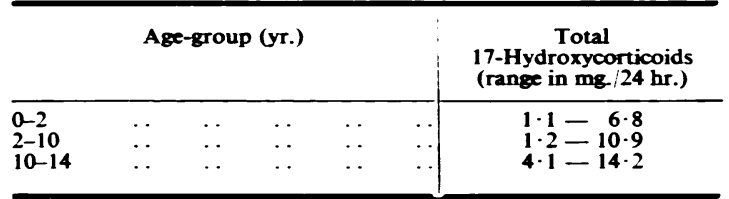

(4) 'Tetrahydro-S'. In patients with an 11hydroxylation defect, this abnormal metabolite is excreted in the urine and can be measured. It is found in the urine of patients with the hypertensive type of congenital adrenal hyperplasia (Bongiovanni and Eberlein, 1955). Administration of the drug, metyrapone ('metopirone'), which blocks 11-hydroxylation, also causes excretion of this metabolite.

(5) 11-oxygenation index measures the ratio of substances without an oxygenation function at the C-11 position to those with such a function, i.e. cortisone and cortisol. The 11-deoxygenated substances include 'compound $S$ ' and 17-x-hydroxyprogesterone and their abnormal metabolites (Hill, 1960). Normally the ratio of 11-deoxygenated to 11-oxygenated substances is $1: 2$ or less. If the ratio becomes reversed, i.e. $2: 1$ or greater, it indicates that there are more precursor substances than there is cortisol and that there must be an accumulation of substances that have not been hydroxylated at the $\mathrm{C}-11$ position. It does not indicate whether the block is at C-11 or C-21. The advantage is that the test can be performed on a random sample of urine (Barratt, Edwards, Makin, and Clayton, 1964).

(6) Two-dimensional paper chromatography can be used to obtain a qualitative indication of the type of enzymatic block present (Edwards, 1960, 1961, 1962).

\section{Review of Cases}

Fifty-eight cases of congenital adrenal hyperplasia have been treated at this hospital to date. Of these, 28 were of the salt-losing type, 29 of the simple type, and 1 of the hypertensive type (Table 4).

Salt-losing Type of Congenital Adrenal Hyperplasia. Of the 28 'salt-losers', 17 were female and 11 were

TABLE 4

INCIDENCE OF DIFFERENT TYPES OF CONGENITAL ADRENAL HYPERPLASIA

\begin{tabular}{lllccc|c}
\hline \multicolumn{2}{c}{ Type } & & & Male & Female & Total \\
\hline Salt-losers & $\cdots$ & $\cdots$ & 11 & & 17 & 28 \\
Simple virilizing & $\cdots$ & $\cdots$ & 13 & & 16 & 29 \\
Hypertensive & $\cdots$ & $\cdots$ & 1 & - & 1 \\
\hline & & & 25 & 33 & 58
\end{tabular}


TABLE 5

THERAPY FOR SALT-LOSING TYPE OF CONGENITAL ADRENAL HYPERPLASIA

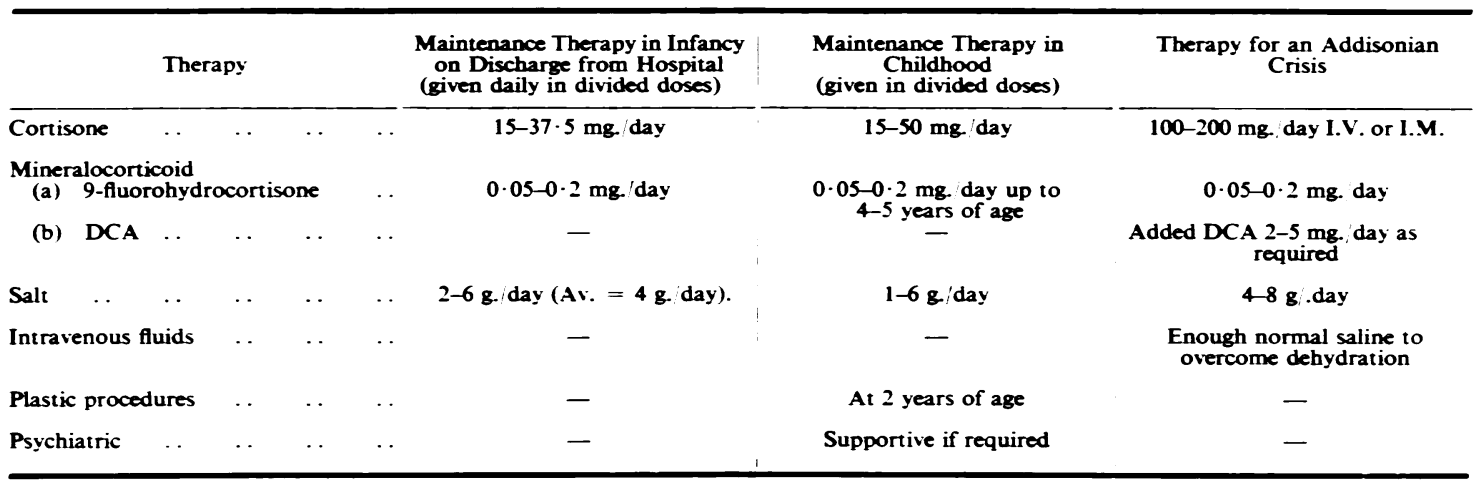

male. All cases were first seen before the age of 3 months. Of these, 7 had presented at the end of the first week of life, and 19 cases by 1 month of age. The presenting symptoms were vomiting, refusal to feed, and weight loss; in addition, 4 were dehydrated enough to require intravenous therapy soon after admission.

All female cases had abnormal genitalia: the clitoris was enlarged and, in several cases, it was mistaken initially for hypospadias. In addition, there was a single urogenital opening, except in one case in which there was a separate vaginal opening and in another in which there was a penile urethra. In the male patients, the genitalia appeared normal on admission, and pyloric stenosis was suspected in the first instance in 6 patients.

Initial investigations were carried out: 24 patients showed initial disturbances in serum electrolytes characterized by a low serum sodium and chloride and high serum potassium, i.e. an Addisonian picture. In 12 of these patients there was an initial raised blood urea which fell to normal limits following treatment. Urinary 17-ketosteroid levels were raised, values varying between $2-5$ and 5-12 mg./24 $\mathrm{hr}$. in 14 and 10 patients respectively (no figures were available for the remaining cases). Pregnanetriol was detected in the urine in amounts varying from $0 \cdot 6-10.5 \mathrm{mg} . / 24 \mathrm{hr}$., in the 13 patients in whom it was estimated. A buccal smear for nuclear sex was performed on 9 patients.

The initial diagnosis was made, therefore, on a history of recurrent vomiting (often projectile in type), refusal to feed, weight loss, abnormal genitalia (if female), an Addisonian type of disturbance of serum electrolytes, and raised 17-ketosteroid and pregnanetriol levels in the urine.

If the child was not dehydrated on admission, investigations were carried out first; if he or she was, therapy (see Table 5) was commenced forthwith, although it is now the practice to try to collect a 4- to 5hour specimen of urine first on which an 11-oxygenation index can be performed. Normal saline was given intravenously to correct the dehydration and to replace salt loss.

Cortisone, which replaces the deficiency of hydrocortisone and also suppresses excessive ACTH secretion by the anterior pituitary gland, was given. Large doses of $100 \mathrm{mg}$./day of hydrocortisone (in divided doses at six-hour intervals) were given intravenously or intramuscularly. After stabilization, cortisone was given by mouth in doses of about $50 \mathrm{mg}$./day, and this was then gradually reduced. The patients, before discharge from hospital, were receiving doses of cortisone varying from 15-37.5 mg./day, given in divided doses at six-hour intervals, though most were given either 25 or $15 \mathrm{mg}$./day. These were found to be the smallest doses of cortisone needed to correct the electrolyte disturbance and to keep the 17-ketosteroid levels down to normal limits for the patient's age. In addition, a salt-retaining hormone was used. Deoxycorticosterone acetate in oil (DCA) was given daily by intramuscular injection in doses varying from 2-5 $\mathrm{mg}$./day. After stabilization, 9- $x$-fluorohydrocortisone in doses of $0 \cdot 1-0 \cdot 2 \mathrm{mg}$./day (given orally in two divided doses) was used instead. Six patients, however, were treated either with a long-acting DCA preparation given by intramuscular injection, or by implants of DCA pellets.

Oral administration of additional salt was also necessary. The patients were given $4 \mathrm{~g}$. salt/day at first, and after stabilization, most were receiving 4-6 g./day. However, 6 patients required as little as 1-2 g./day, and 2 were receiving $8 \mathrm{~g}$./day.

After discharge from hospital, patients were seen at fortnightly and then monthly intervals and later at 
two-monthly and then at three-monthly intervals. At each visit, weight and height were measured and these were plotted on a percentile chart, thus providing a follow-up of the developmental progress. In addition, urinary 17-ketosteroids and total 17-hydroxycorticoids were measured at six-monthly intervals, the 24-hour urine specimen being collected at home and sent by post. Bone age was estimated by radiography of the left wrist at six-monthly intervals. Steroid therapy was adjusted according to body height, bone age, and urinary 17-ketosteroid estimations, the aim being to keep these within normal limits wherever possible, and to give the smallest dose of steroids necessary to achieve this.

Twelve of our patients have been followed to the age of 4 years. Of these, 9 were receiving cortisone in doses of $15-30 \mathrm{mg}$./day, 2 were receiving $37.5 \mathrm{mg}$./ day, and 1 needed $50 \mathrm{mg}$./day. Only 4 of the 12 patients still needed a salt-retaining hormone at this age. All were still maintained on added salt in doses of $1-4 \mathrm{~g}$./day.

Of these 12 patients, 5 have reached the age of 8 years. The dose of cortisone required at this age was $50 \mathrm{mg}$./day in 2 , and $37.5 \mathrm{mg}$. in 3 . The saltretaining hormone had been stopped, but all were still having extra salt.

Complications of therapy were recorded in several cases. One child was given an implant of $500 \mathrm{mg}$. of DCA, at the age of 4 months: hypertension developed within a month, but the blood pressure returned to normal within 6 months. A second patient, who was maintained on $5 \mathrm{mg}$. of DCA daily by injection, at the age of 2 months (in 1953), developed hyperelectrolytaemia within a week. In
1955, 4 patients were treated with fluorodihydrocortisone alone (then a new drug). Two were not followed up because they left England. The other two died (see discussion of deaths). 9- $x$-fluorohydrocortisone (which differs from above) when given in suppressing doses of 1-2 mg./day has caused hypertension in 2 of our cases (Owen, Engel, and Wester, 1957).

Corrective surgery in female patients, was carried out at ages varying from 1 to 5 years, though it is now the practice to perform a subtotal clitoridectomy at the age of 18 months to 2 years, i.e. when there has been adequate control and management of the patient. A plastic operation is performed on the vagina at the same time.

Associated disorders have been found in 4 children: one developed convulsions at the age of $2 \frac{1}{2}$ years and died at the age of 3 . A second child had a persistent urinary tract infection. Intravenous pyelogram showed hydronephrosis on the left side. A third child was mentally retarded and blind from birth. A fourth child, admitted at the age of 3 weeks, was dehydrated and convulsing and developed a left hemiplegia; maintenance therapy with phenobarbitone was required to control the fits. Subsequently he was found to be mentally retarded.

Eight of the salt-losers (4 female and 4 male) have died (Table 6). One girl (1955) was treated with cortisone, DCA, and salt; she died at the age of 16 months, but no further information is available. The second (1955) was stabilized on the above régime also. Her treatment was then changed to fluorodihydrocortisone and salt only. She was admitted early in 1956, following an acute upper

TABLE 6

ANALYSIS OF DEATHS

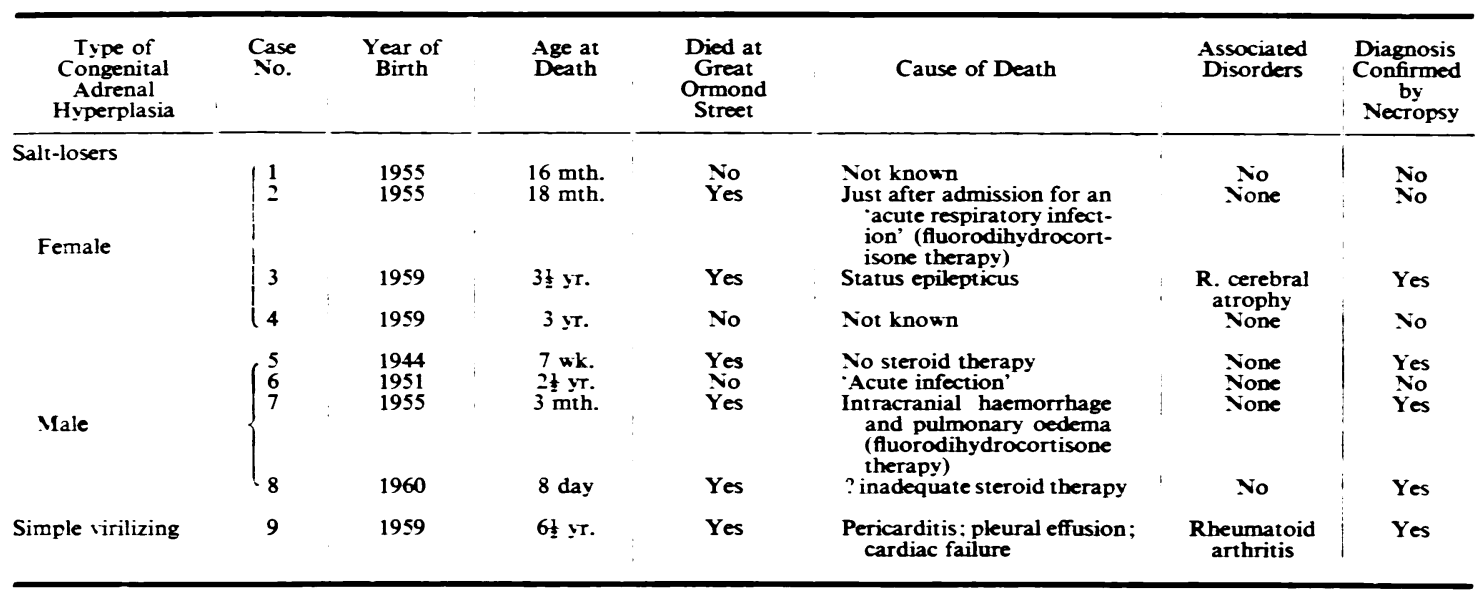


TABLE 7

DIAGNOSIS AND FOLLOW-UP OF CONGENITAL ADRENAL HYPERPLASIA

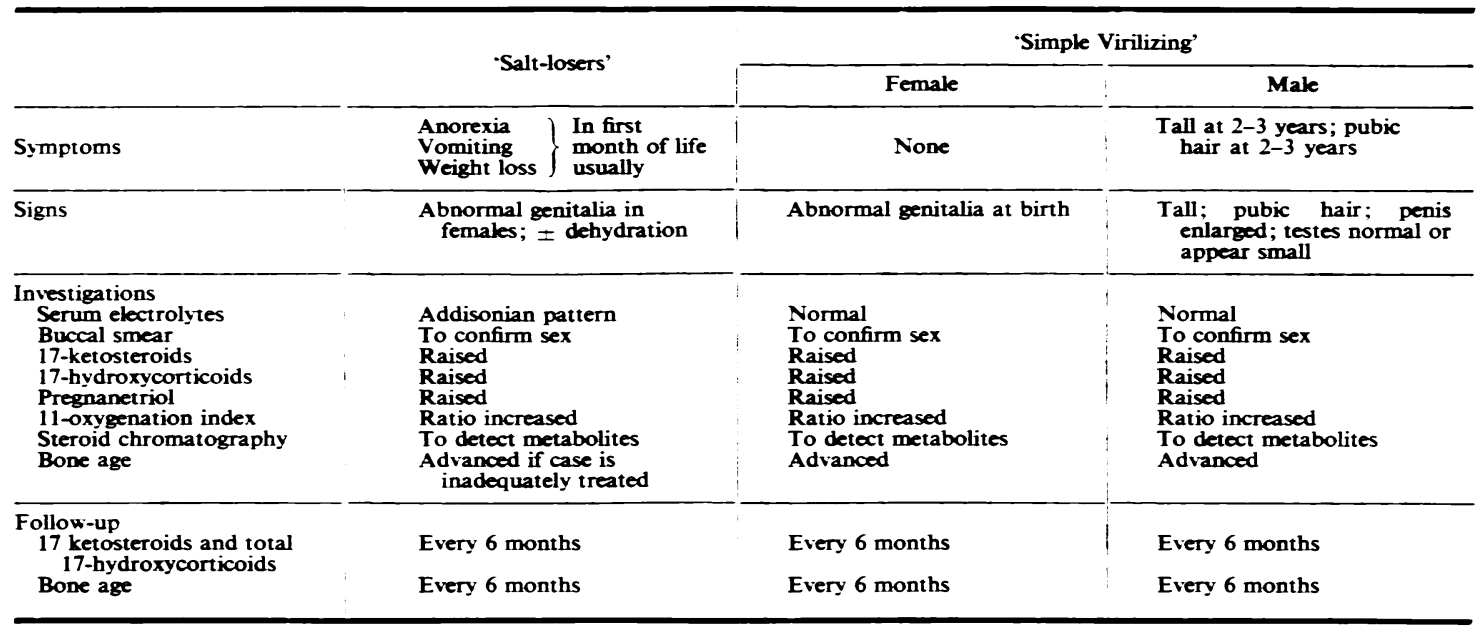

respiratory tract infection, but she died soon after arrival. The third girl (1959) developed convulsions at the age of $2 \frac{1}{2}$ years, and anti-epileptic treatment was required; in her final illness she was admitted in status epilepticus. Necropsy showed atrophy and gliosis of the right cerebral hemisphere. The fourth girl (1962) was also 3 years old when she died. She was not admitted to this hospital during her final illness and notes are not available, but she was thought to have had 'gastro-enteritis' before death.

The first male patient (1944) was admitted at 3 weeks of age, before cortisone therapy was available. He was kept alive for four weeks, requiring intravenous therapy for most of the time. The correct diagnosis was confirmed at necropsy. The second patient (1951) was seen soon after birth. He was stabilized on the treatment then available. However, at the age of $2 \frac{1}{2}$ years he died quite suddenly following an acute infection for which he was not admitted to hospital. The third male patient (1955) was correctly diagnosed and treated. His therapy was then changed to fluorodihydrocortisone and salt only. He became hypertensive and began to convulse. Blood-stained cerebrospinal fluid was found. He died four days later. At necropsy, intracerebral haemorrhage affecting the right cerebral hemisphere and right basal nuclei, was found, in addition to adrenal cortical hyperplasia. The fourth male patient (1960) was admitted on the eighth day of life in a dehydrated state. The diagnosis of congenital adrenal hyperplasia was made and intravenous therapy, including steroids, was instituted. He appeared to respond, but during the night he again went into peripheral circulatory failure and died. It appears, in retrospect, that he was undertreated.

Simple Virilizing Type of Congenital Adrenal Hyperplasia. Of the 29 patients in this category in our series, 13 were male and 16 were female. All boys with one exception presented at $5 \frac{1}{2}-7$ years of age with the complaint that they were tall for their age. All had well-developed pubic hair, but no axillary or facial hair, or acne; the penis was large but the testes were normal and the bone age was advanced to the level of 13-14 years. There was an increase in the level of urinary 17-ketosteroids, 17-hydroxycorticoids, and pregnanetriol. Buccal smears were performed routinely and these confirmed that all the patients were male. Serum electrolyte estimations were normal in all cases. In retrospect, the parents, in each case, stated that when the child was $2 \frac{1}{2}-3$ years of age, they noticed that he was taller than other children, and that pubic hair had begun to appear. One patient was brought by his parents at the age of $2 \frac{1}{2}$ years because he appeared tall. His bone age was then $9 \frac{1}{2}$ years. By the age of 3 years, pubic hair was noticed.

The heights of all boys were above the 97th percentile when first seen, and were at the 50th percentile for a child of between 10 and 11 years. In all the boys, the initial 17-ketosteroid values varied between 10 and $40 \mathrm{mg}$. $/ 24 \mathrm{hr}$. In addition, 8 of these 13 patients showed large amounts of pregnanetriol, values varying between 10 and $30 \mathrm{mg}$./day The initial total 17-hydroxycorticoids were measured in three cases, the values being 41,63 , and $93 \mathrm{mg}$. $/ 24$ hours respectively. 
Laparotomy and testicular biopsy were performed on three boys in order to exclude tumours. Skull radiograph was normal in all patients. An ACTH and a cortisone suppression test were performed on 6 patients: the ACTH test showed no significant change in the 17-ketosteroid output in the urine, whereas cortisone caused a marked drop in the 17-ketosteroid levels and the disappearance of urinary pregnanetriol.

Eight boys were treated with cortisone by mouth in doses of $\mathbf{4 0 ~ m g}$./day, and 3 were given doses of $\mathbf{5 0}$ mg./day. Two were treated with prednisolone 10 mg./day. All patients were maintained on this dose throughout except for 3 in whom the dose was increased to $75 \mathrm{mg}$. cortisone per day. The aim of treatment has been to lower the production of androgenic substances (as measured by urinary 17ketosteroid excretion) to normal limits for age and hence to slow down the rapid rate of bone growth and development.

One patient fractured the midshaft of his left ulna at the age of 7 years. He had been receiving steroids for 6 months. By the age of 9 years, the fracture was still not united. Steroid therapy was then stopped, in an attempt to facilitate healing of the fracture.

One boy died. Six months after commencing treatment with steroids he developed symptoms and signs of rheumatoid arthritis. The dose of cortisone was increased to $300 \mathrm{mg}$./day and subsequently reduced gradually to $62.5 \mathrm{mg}$./day. There was a remission followed by a relapse three months later, during which he died. At necropsy, the diagnoses of congenital adrenal hyperplasia and of rheumatoid arthritis were confirmed. In addition, there was evidence of pericarditis and pleurisy, the clinical signs of which were present before death.

In the affected girls, the age of presentation differed from that of the boys, as they were referred because of abnormal genitalia. Of 16 girls, 9 were first seen before they were 2 months old, 4 presented at about 4 years, and the other 3 presented at 7 years, $7 \frac{1}{2}$ years, and 9 years, respectively. The serum electrolytes were normal. The 17-ketosteroid values were raised, the levels varying between 2.5 and 30 $\mathrm{mg} . / 24 \mathrm{hr}$. Pregnanetriol was found in the urine of those in whom it was estimated. Seven girls were treated with prednisolone, the dose varying from $2 \cdot 5$ to $10 \mathrm{mg}$./day. The remaining girls were treated with cortisone, the dose varying from 25 to $50 \mathrm{mg}$./ day. Because of the earlier age of presentation and initiation of treatment, the heights of these patients were maintained at about the 50th percentile for age and sex.

One girl was born with a hare-lip and cleft palate.
Another patient was mentally retarded. There were no deaths in this group.

Hypertensive Type of Congenital Adrenal Hyperplasia. We have only one patient who belongs to this group. He was born in 1946, and at birth he was thought to be a male. In 1949, plastic surgery for hypospadias was performed. He was then lost to follow-up, and was not seen again until 1957, i.e. when 11 years old. It was then noticed that he had hypertension. His buccal smear showed that his sex was female. His height was on the 97th percentile and his blood pressure was $200 / 140 \mathrm{~mm}$. Hg. Pubic and axillary hair were present. His 17-ketosteroid level was $30 \mathrm{mg}$. $/ 24 \mathrm{hr}$. and compound ' $S$ ' was found in excessive amounts in his urine. Following treatment with cortisone $50 \mathrm{mg}$./day, there was some fall in blood pressure. Later reserpine was added. Soon after cortisone therapy was commenced, he began to menstruate and so his ovaries were irradiated in order to stop menstruation. This procedure was unsuccessful. A few months later, a panhysterectomy was performed.

The child's blood pressure is now $130 / 95 \mathrm{~mm} . \mathrm{Hg}$, and his 17-ketosteroids have fallen to $2.4 \mathrm{mg}$. $/ 24 \mathrm{hr}$. His height has levelled off progressively to the 3rd percentile for age and sex. He is now receiving prednisolone $10 \mathrm{mg}$./day and reserpine $0.5 \mathrm{mg}$./day, both in divided doses. He has a high I.Q., and his sex orientation is entirely male.

\section{Discussion}

Patients with the salt-losing type of congenital adrenal hyperplasia develop symptoms early, usually within the first month of life and often earlier. The clinical features are characteristic, i.e. recurrent vomiting which may appear projectile, refusal to feed, and loss of weight. There may be rapid onset of dehydration. The serum electrolyte pattern characteristic of an Addisonian crisis develops early in most patients. The electrolyte picture helps to confirm one's suspicions and also aids in differentiating from congenital hypertrophic pyloric stenosis, particularly in the male. It must be stressed that ward tests for urinary chloride output are unreliable for differentiating from the latter disorder. The results can be very misleading and, for this reason, the test is no longer used.

Urine should be collected for 17-ketosteroid, total 17-hydroxycorticoid, and pregnanetriol estimations. Two-dimensional paper chromatographic study of the steroid excretion pattern should be undertaken, since it is known that some cases of congenital adrenal hyperplasia may have a normal 17-ketosteroid output during the early weeks of life. With 
chromatography one can detect the presence and type of abnormal metabolites. The determination of the 11-oxygenation index is also a useful procedure. It is particularly suitable for those patients from whom only a 4 - or 5-hour urine specimen can be obtained because they are dehydrated and require urgent treatment.

After initial stabilization most of our patients have been treated with oral preparations. Cortisone is used because it has greater salt-retaining effects than does prednisolone. 9-x-fluorohydrocortisone has proved to be a useful salt-retaining hormone when used in smaller doses of 0.05 to $0.2 \mathrm{mg}$./day. Added salt of the order of $4 \mathrm{~g}$. per day is also required.

It is interesting to note that only 4 of 12 patients were receiving a mineralocorticoid at the age of 4 years and that none of the 5 patients followed to 8 years of age or more were receiving any salt-retaining hormone. It seems that after 4-5 years of age, added salt-retaining hormone is not necessary. Oral steroids are preferred to long-acting DCA depot preparations.

Triamcinolone has not been used in our series but has been used in the U.S.A. Its side-effects include muscle weakness, hirsutes, psychosis, and papilloedema (Dees and McKay, 1959). Long-acting preparations such as hydrocortisone acetate (Litman and Donnell, 1960) and prednisolone trimethylacetate (Dingman, Maranan, and Staub, 1962) have not been used by us. Fluorodihydrocortisone has not been used since 1955. At the time, it was thought that this drug would have the effects both of cortisone and of a mineralocorticoid.

It is now our practice to treat the infants on the following lines. After diagnosis and investigations (i.e. collection of blood and urine for further studies, etc.), treatment is carried out. Possible complications of the disorder are explained to the parents. If the child becomes feverish, anorexic and/or vomits, the parents are asked to double the dose of cortisone by mouth immediately, and this is often continued for several days. If the drug is vomited or if further difficulties arise, medical help should be sought. Early admission to hospital is advisable and treatment for an impending Addisonian crisis can be instituted as shown in Table 5. Diagnostic and follow-up procedures are summarized in Table 7.

Surgical procedures on girls are now performed at the age of 18 months to 2 years when there has been adequate stabilization and control. At the same time a plastic operation is performed on the vagina.

A considerable amount of study has been devoted to determining the cause for salt loss. Eberlein (1958) has pointed out that these patients differ from those with Addison's disease in that more salt- retaining hormone is required for treatment of children with congenital adrenal hyperplasia than is needed for adults with Addison's disease. Bongiovanni and Eberlein (1958) showed that a severer degree of defect in the production of cortisol occurred in patients with the salt-losing type of the disorder than in patients with the simple virilizing type and suggested that this might be related to the severity of the enzyme defect. Bongiovanni also postulated that there might be a salt-losing factor produced by the adrenals in most patients with congenital adrenal hyperplasia, but that compensation occurred if aldosterone production could be increased. Blizzard et al. (1959) have shown that patients with the virilizing type can respond to a lowsalt diet by increasing their aldosterone excretion, but that patients with the salt-losing type excrete deficient amounts of aldosterone as compared with normal subjects and that they are unable to respond to a low-salt diet with any significant increase in aldosterone excretion. Bryan, Kliman, and Bartter (1962) have demonstrated evidence for impaired aldosterone production in the salt-losing type.

The same enzyme, 21-hydroxylase, is required in the pathway for formation both of hydrocortisone and of the salt-retaining hormones, corticosterone and aldosterone. No added salt-retaining hormone is needed after 4-5 years of age, and so it is possible that either there is partial recovery of this enzyme system or that an alternative metabolic pathway is developed to allow production of sufficient saltretaining hormone.

We draw attention to the observation that infants with the salt-losing type of congenital adrenal hyperplasia require $15-37 \cdot 5 \mathrm{mg}$. cortisone per day for treatment. This is five to ten times the normal hydrocortisone production rate as measured by Kenny et al. (1963). It may be assumed that a proportion of the drug is not absorbed. However, adults either with Addison's disease or who have had total adrenalectomy usually only require $12 \cdot 5-50$ mg./day of cortisone for replacement therapy, i.e. the equivalent of, or only double, the normal hydrocortisone production rate for an adult. It appears that cortisone is needed not only for replacement but also for its suppressive effect on ACTH and androgen production.

In the simple virilizing type of the disorder, the female presents early, usually during the first or second month of life because the abnormal genitalia are so easily recognized. If treatment is begun, a normal pattern of somatic (including skeletal) growth occurs.

Male patients have presented late, i.e. when the child's height is obviously out of proportion to the 
child's age. The increased height and growth of pubic hair are manifest by 3 years of age. The bone age is then already 7 to 8 years. Diagnosis ought to be made by this age and treatment instituted in order to retard further excessive advance of bone age and to check the development of secondary sexual characteristics. If the diagnosis is not made until 5 to 6 years of age then, in addition, one will find enlargement of the penis with infantile testes, and the bone age will be 12 to 13 years. Facial and axillary hair do not appear until 7 to 8 years of age. Management becomes less satisfactory because, although the rapid rate of bone growth can be retarded, it is likely that epiphyses will fuse early and that these boys will become dwarfed adults. In addition, steroid therapy may induce adolescent development of the testes and full puberty may take place within a few months of commencing therapy.

It is now our practice to treat these children with prednisolone. Larger suppressive doses are required at first, and cortisone in doses of $100 \mathrm{mg}$. per day has been used in the first instance, until the urinary 17-ketosteroid output falls to normal levels for age and remains normal. The maintenance dose of steroids varies with age but appears to be of the order of 5-15 mg. of prednisolone per day.

Treatment is continued beyond puberty in order to allow fertility, since excessive androgenic production will suppress gonadotrophic activity. Moreover, these patients have defective production of hydrocortisone and therefore require glucocorticoid replacement therapy. They are unable to respond normally during such stresses as acute infections or surgery, and therefore require increased doses of steroids. If this need is not met, they will undergo an Addisonian crisis which will resemble the saltlosing type of the disorder, and they will require treatment on the same lines as previously indicated.

Occasionally, an adrenal adenoma may present with clinical features similar to those of simple virilizing type of congenital adrenal hyperplasia. A cortisone suppression or preferably a dexamethasone suppression test is carried out. If the patient has an adenoma, there will be no fall in the output of 17-ketosteroids and total 17-hydroxycorticoids. But in patients with congenital adrenal hyperplasia who present at 5 or 6 years of age, cortisone in doses of $100 \mathrm{mg}$./day, or its equivalent, may have to be given for several weeks or even a month, before the urinary 17-ketosteroids can be suppressed to normal levels.

Before the introduction of steroid therapy at the beginning of the last decade it was generally felt that, because these children have so many masculine features they should be brought up as males (Wilkins,
1957). Adequate suppression therapy is now available, and the females now can and should be reared as girls. In cases where a mistake in the sex is made (which occurs more rarely now), and the child is reared as a boy, change of sex should not be contemplated after 2 years of age (Money, Hampson, and Hampson, 1955). Such children develop a normal male sex orientation.

Several of the children required psychotherapy. This was more often needed for girls of 4 to 5 years of age who still had an enlarged clitoris. These children had noticed that they were different from other girls of their age and that their genitals resembled those of their male playmates. Boys with the simple virilizing type of congenital adrenal hyperplasia and who were not diagnosed until 5 to 7 years of age also had psychological difficulties. Their I.Q. was normal for their age, but because their stature was that of a child of 10-11 years, many people had expected them to behave and act accordingly and therefore the children appeared to be mentally retarded.

Genetic studies were carried out. In the saltlosing type of the disorder, 8 of the 25 sibs of index patients were probably affected. A study of the families of patients with the simple virilizing type showed that 7 of the 35 sibs of index patients were similarly affected.

\section{Summary}

Our series of 58 patients suffering from congenital adrenal hyperplasia have been reviewed. These consist of 28 cases of the salt-losing type, 29 cases of the simple virilizing type, and 1 case of the hypertensive type. The presenting features and the differences in clinical features between male and female cases have been outlined, the causes of deaths have been discussed, and an outline of treatment and further management has been given.

We wish to thank Professor Alan A. Moncrieff, Professor A. W. Wilkinson, Mr. D. I. Williams, and Drs. P. R. Evans, R. Lightwood, A. P. Norman, and B. Schlessinger who allowed us to include their cases. Our thanks also go to Dr. Cedric O. Carter who helped with the genetics and to Drs. B. Clayton, R. W. H. Edwards, and Stanley A. Plotkin for their help, advice, and criticism. We thank Mr. H. L. J. Makin for his help with 11-oxygenation index. We also wish to acknowledge the biochemical work done by Drs. W. W. Payne and $R$. H. Wilkinson. We are indebted to the Department of Medical Illustration for their help with the diagrams. One of us (Dr. S. Raiti) acknowledges financial assistance received from The Welkome Trust during the course of this work.

\section{Rerenencas}

Barratt, T. M., Edwards, R. W. H., Makin, H. L. J., and Clayton, B. E. (1964). The clinical varieties of adrenal hyperplasia in children. J. Endocr., 29, xi. 
Bartter. F. C., Albright. F.. Forbes, A. P.. Leaf, A. O., Dempsey, E. and Carroll, E. (1951). The effects of adrenocorticotrophic hormone and cortisone in the adrenogenital syndrome associated with congenital adrenal hyperplasia: An attempt to explain and correct its disordered hormonal pattern. J. clin. Invest., 30, 237.

Blizzard, R. M.. Liddle. G. W.. Migeon, C. J. and Wilkins, L. (1959). Aldosterone excretion in virilizing adrenal hyperplasia. ibid., 38. 1442.

Bongiovanni. A. M. (1958). Congenital defects in adrenal steroid synthesis. Pediatrics. 21. 1031.

- (1961). Unusual steroid pattern in congenital adrenal hyperplasia: Deficiency of 3-beta-hydroxy dehydrogenase. J. clin. Endocr.. 21, 860.

- and Eberkin. W. R. (1955). Clinical and metabolic variations in the adrenogenital syndrome. Pediatrics, 16. 628.

- (1958). Defective steroidal biogenesis in congenital adrenal hyperplasia. ibid., 21, 661 .

- and Kellenbenz, G. (1962). The adrenogenital syndrome with deficiency of 3-beta-hydroxysteroid dehydrogenase. J. clin. Invest., 41, 2086

Bryan. G. T., Kliman. B. and Barter, F. C. (1962). Impaired aldosterone production in 'salt-losing' congenital adrenal hyperplasia. Clin. Res.. 10. 223.

Butler. A. M., Ross, R. A. and Talbot. N. B. (1939). Probable adrenal insufficiency in an infant: Report of a case. J. Pediat., 15. 831 .

Clayton. B. E.. Edwards. R. W. H. and Renwick. A. G. C. (1963). Adrenal function in children. Arch. Dis. Childh., 38. 49.

Childs. B.. Grumbach. M. M. and Van Wyk. J. J. (1956). Virilizing adrenal hyperplasia; a genetic and hormonal study. $J$. clin. Invest., 35, 213.

Dingman. J. F., Maranan. L. C. and Staub, M. C. (1962). Treatment of adrenogenital syndrome. Intramuscular therapy with longacting prednisteroids. J. Amer. med. Ass., 180. 1017.

Dees. S. C. and McKay, H. W. (1959). Occurrence of pseudotumour cerebri (benign intracranial hypertension) during treatment of children with asthma by steroids. Pediatrics, 23, 1143.

Eberlein. W. R. (1958). The salt-losing form of congenital adrenal hyperplasia. ibid.. 21, 667.

- and Bongiovanni, A. M. (1955). Congenital adrenal hyperplasia with hypertension: Unusual steroid pattern in blood and urine. J. clin. Endocr., 15, 1531.

Edwards, R. W. H. (1960). In Chromatographic and Electrophoretic Techniques, 2nd ed., by I. Smith, pp. 409-446. Heinemann, London.

- (1961). Steroid chromatography in two dimensions. $J$. Endocr., 22, XXVI.

(1962). Two-dimensional chromatography of corticosteroids. Biochem. J., 82, 48P.

Fibiger, J. (1905). Beitrāge zur Kenntnis des weiblichen Scheinzwittertums. Virchows Arch. path. Anat, 181, 1.
Frantz. A. G.. Holub, D. A. and Jailer. J. W. (1960). Further evidence of a relative lack of C-21 hydroxylation in congenital adrenal hyperplasia. J. clin. Invest.. 39. 904.

Grumbach. M. M. and Wilkins. L. (1956). The pathogenesis and treatment of virilizing adrenal hyperplasia. Pediatrics, 17, 418.

Hill, E. E. (1960). Chromatography of the 17-ketogenic steroids in the diagnosis and control of congenital adrenal hyperplasia. Acta endocr. (Kbh.), 33, 230.

Jaiker, J. W., Gold, J. J., Vande Wiele. R. and Lieberman, S. (1955). 17-alpha hydroxyprogesterone and 21-desoxyhydrocortisone: Their metabolism and possible role in congenital adrenal virilism. J. clin. Invest., 34, 1639.

- Louchart, J., and Cahill, G. F. (1952). Adrenal virilism. II. Metabolic studies. ibid., 31, 880 .

Kenny, F. M.. Malvaux, P. and Migeon. C. J. (1963). Cortisol production rates in newborn babies, older infants, and children. Pediatrics, 31, 360.

Litman. N. N. and Donnell. G. N. (1960). Treatment of congenital adrenal hyperplasia with concentrated hydrocortisone acetate. J. clin. Endocr., 20, 862.

Money, J.. Hampson. J. G. and Hampson. J. L. (1955). Hermaphroditism: Recommendations concerning assignment of sex. change of sex, and psychologic management. Bull. Johns Hopk. Hosp. 97.284.

Owen, J. A., Engel, F. L. and Wester. T. B. (1957). 9-alpha-fluorohydrocortisone-induced hypertension in a male infant with adrenogenitalism. and in six adults with Addison's disease. J. clin. Endocr.. 17. 272

Peterson, R. E. (1957). Plasma corticosterone and hydrocortisone levels in man. ibid., 171150.

- and Wyngaarden, J. B. (1956). The miscible pool and turnover rate of hydrocortisone in man. J. clin. Invest., 35, 552.

Phillips, J. (1887). Four cases of spurious hermaphroditism in one family. Trans. Obstet. Soc. Lond., 1886, 28, 158.

Prader, A. and Siebenmann. R. E. (1957). Nebenniereninsuffizienz bei Kongenitaker Lipoidhyperplasie der Nebennieren. Helv. paediat. Acta, 12, 569.

- Spahr. A. and Neher, R. (1955). Erhōhte Aldosteronausscheidung beim kongenitalen adrenogenitaken Syndrom. Schweiz. med. Wschr., 85, 1085.

Prout, M. and Snaith. A. H. (1958). Urinary excretion of 17 ketosteroids in children. Arch. Dis. Childh.. 33, 301.

Snydor, K. L., Kelley, V. C., Raile, R. B., Ely, R. S., and Sayers, G. (1953). Blood adrenocorticotrophin in children with congenital adrenal hyperplasia. Proc. Soc. exp. Biol. (N.Y.), 82, 695.

Wilkins. L. (1957). The Diagnosis and Treatment of Endocrine Disorders in Childhood and Adolescence, 2nd ed. Thomas, Springfield. Illinois.

- (1962). Adrenal disorders: II. Congenital virilizing adrenal hyperplasia. Arch. Dis. Childh., 37, 231.

- Lewis. R. A.. Klein. R. and Rosemberg. E. (1950). The suppression of androgen secretion by cortisone in a case of congenital adrenal hyperplasia. Bull. Johns Hopk. Hosp., 86, 249. 